bien, como base para diseñar un modelo de presencia de los católicos en la vida política entendida en un sentido amplio. Ese es su objetivo último. Y creo que se aborda bien el problema real, no sólo con las aportaciones insustituibles del Concilio, sino con los nuevos elementos que nos suministran los años más recientes.

Ildefonso Camacho Laraña, S.J.

\section{CIENCIA POLÍTICA}

Porras Nadales, A.J. (Dir.) (1998), $E l$ Parlamento de Andalucía: Claves de un proceso institucional, Parlamento de Andalucía, Sevilla, 302 págs.

El presente libro constituye un informe elaborado por un grupo de expertos en Derecho Constitucional dirigidos por el profesor Antonio Porras Nadales, destacado especialista en los estudios relacionados con la estructura política de la Comunidad Autónoma Andaluza. El informe fue realizado a petición de la Mesa del Parlamento de Andalucía, que pretendía promover una reflexión sería e independiente sobre la labor realizada por el Parlamento andaluz en el decimoquinto aniversario de su constitución.

El libro que reseñamos sigue un esquema expositivo claro y perfectamente definido. Comienza con un capítulo in- troductorio que describe sucintamente los avatares de la vida política de la Comunidad Autónoma Andaluza: los primeros impulsos autonómicos, el diseño institucional, los desafíos principales a los que se enfrentaba la recién nacida institución parlamentaria, las directrices políticas esenciales que marcaron las distintas legislaturas. El capítulo termina destacando lo que, en opinión de los autores, constituyen las principales pautas que reflejan lo que ha venido a ser un "un proceso constructivo de aprendizaje parlamentario": el predominio creciente de debates parlamentarios de tipo sectorial y especializado en detrimento de debates de tipo más general y retórico con fuerte carga ideológica; la presión permanente del Parlamento por tener una mayor presencia en los nombramientos institucionales; y la tendencia a acelerar "la gestión de agenda o timing de la Cámara sobre temas o asuntos de actualidad".

En el capítulo I, titulado "Estructura y composición: el Reglamento", se analiza la estructura y composición que el Parlamento ha tenido en cada una de las legislaturas ya concluidas. Asimismo se pone de relieve la regulación que sobre los sujetos parlamentarios, la organización interna del Parlamento, las funciones del Parlamento y las reglas generales de funcionamiento de la Cámara han establecido los tres Reglamentos que han regido el Parlamento andaluz.

El capitulo II lleva por título "La función legislativa en el Estado autonómico", y aborda la producción normativa 
que ha tenido lugar en los 17 parlamentos autonómicos españoles desde su creación. Resultan de gran interés las conclusiones que se extraen respecto a las características que concurren en esta actividad legislativa, tanto en lo referente a las materias objeto de regulación como en lo concerniente a la determinación del tipo de estrategia técnico-jurídica que utiliza el legislador autonómico para perseguir los objetivos programáticos formulados a nivel político. Constituye un capítulo muy clarificador de lo acontecido en nuestro país en lo que se refiere a las características que concurren en la legislación que dimana de los parlamentos autónomos.

En el capítulo III se analiza de forma específica "La actividad legislativa del parlamento de Andalucía". En el mismo se exponen ordenadas por legislaturas las leyes aprobadas por el Parlamento, las enmiendas a la totalidad presentadas por los grupos de la oposición (lo que viene a reflejar el rendimiento legislativo de la oposición en su dimensión global), los proyectos de ley decaídos o retirados (lo que puede considerarse como el "rendimiento 'negativo' de la Cámara"), y las proposiciones de ley a través de los cuales los grupos de la oposición formulan sus "proyectos de diseño legislativo". El capítulo concluye con una exposición de las leyes del Parlamento de Andalucía que han sido cuestionadas ante el Tribunal Constitucional por su posible inconstitucionalidad.

El capítulo IV se dedica a estudiar las otras grandes funciones que tiene el Parlamento de Andalucía: las de debate (tanto en pleno como en comisiones) y control (a través de interpelaciones, mociones, preguntas orales y escritas). Resulta sugerente el análisis de las proposiciones no de ley, concebidas como estadio intermedio entre las funciones generales de debate y las estrictas funciones de control. Especial interés tiene la explicitación de las pautas de evolución que las funciones de debate y control han tenido en los quince años que se analizan.

El último capítulo, cuyo título es "Centralidad institucional y desarrollo democrático", analiza en primer lugar las medidas que el Parlamento de Andalucía ha adoptado a través de la legislación de incompatibilidades y el denominado Registro de Intereses con el objeto de someter a control a la "clase política". Asimismo se estudia la figura del Defensor del Pueblo de Andaluz, la Cámara de Cuentas de Andalucía y la Oficina Presupuestaria en tanto constituyen instituciones externas de control de la actividad política andaluza. En segundo lugar se estudian y valoran las innovaciones que ha introducido la Cámara andaluza para fomentar la participación directa de los ciudadanos y grupos sociales: audiencias a sectores sociales, preguntas de iniciativa ciudadana, etc. El capítulo y la obra concluyen con unas consideraciones finales sobre la forma de gobierno que se ha venido configurando en Andalucía en la sesquidécada que es objeto de estudio, plan- 
teándose asimismo algunas alternativas que pueden suponer un "avance innovativo y sustancial hacia la democracia del futuro".

En resumen, nos encontramos ante un trabajo de indudable rigor y profundidad. Tremendamente útil para conocer con detalle lo acontecido políticamente en Andalucía en los últimos quince años. Que permite al lector formase una idea muy fundamentada no sólo de una secuencia o sucesión de hechos perfecta- mente sistematizados y expuestos, sino también de la valoración que desde la ciencia política se hace de los mismos, siempre a partir de la independencia y rigor de los autores. Entiendo por ello que los autores de la obra han cumplido plenamente con el encargo que les hizo el Parlamento andaluz de realizar una reflexión sería e independiente sobre la actividad del Parlamento de Andalucía.

Julio Jiménez Escobar 